Impact Factor 4.989 (SJIF)

UGC Approved Journal No. 63640

\title{
Effects of Cadmium heavy metal on Protonemal Growth and bud formation in The Moss Hydrogonoumarcuatum (Griff.) Wijk. \& Marg
}

\author{
Preet Rachna* , B. D.Vashistha** \\ "Deptt. of Botany, Dyal Singh College, Karnal, Haryana, India \\ ${ }^{* *}$ Deptt. of Botany, Kurukshetra University, Kurukshetra, Haryana, India \\ E-mail: rachna.preet@gmail.com
}

\begin{abstract}
The present study was conducted to investigate the toxicity of Cadmium salts on the growth parameters of Hydrogoniumarcuatum. For this purpose selected moss tissue were acclimated to the laboratory conditions by culturing onNitsch's basal medium supplemented with various salts of Cadmium in the specific concentration range $10^{-8}-10^{-4} \mathrm{M}$. In the present study various morphological changes in the moss such as Protonemal abnormality and formation of brood cells like structures were observed and bud formation was adversely affected. These changes can be used to study heavy metal pollution.

Keywords: Hydrogonium, brood cells, Cadmium salts, morphological effects
\end{abstract}


Effects of Cadmium heavy metal on protonemal growth and bud formation in The Moss Hydrogonoumarcuatum (Griff.) Wijk. \& Marg

Preet Rachna and B.D. Vashistha

\section{Introduction}

Pollution of air, water and soil, caused mainly by increasing industrialization, has become a matter of global concern. Pollution monitoring without knowing their source of emission is a complex problem (Borutet al. , 2002; Giordano et al., 2005 \&Tripathi \& Gautam, 2007). Heavy metal pollutantswere emitted by fuel combusion, vehicular emission and industrial processes which causes adverse affects on our environment.

Bryophytes are suitable biomonitors of pollution as they have rapid absorption rate, lack of roots, show absorption through plant surface and differential ability to accumulate wide range of metals etc. In last few years, the use of bryophytes as pollution monitors (Richardson, 1981) has been emphasized due to the potentiality of these plants to accumulate the toxic elements ( Martin \& Cougerty, 1982; Ruhling\& Tyler, 1984).

Since only a few studies on the effect of heavy metals on bryophytes has been carried out (Kapur\& Chopra, 1989; Ghate\&Chaphekar, 2000) and hence further studies need to carried out for detection of heavy metal pollution by using morphological changes which bryophytes undergo. So the present study was carried out to understand the effect of some heavy metal on various phases of development of the moss Hydrogoniumarcuatum under in vitro conditions.

\section{Materials and Methods}

Fresh moss plants were collected from north western parts of India.
Sporophytes with operculum intact were detached and washed in running tap water for 2-3 $\mathrm{h}$ followed by surface sterilization with chlorine water for 1 minute and than by sterilized double distilled water 3-5 times. Capsules were raised from spores. In the sterile environment intheLaminar hood. They were squeezed out of capsules on a sterile glass slide and planted aseptically on a semi -solid NB medium with pH 5.8 adjusted before autoclaving, and contains Knop's major salts , Nitsch's trace elements, Ferric citrate, Sucrose and Agar.

After spore germination one of the cultures was selected and its protonemata were subcultured for further experimentation. A small amount of budfree protonema was used as inoculums in each test tube. This was inoculated in sterile nutrient medium containing heavy metals in different concentrations (ranging from 10${ }^{8}$ to $10^{-4} \mathrm{M}$ ) individually. The experimental cultures were maintained for 60 days in culture room at $25 \pm 2^{\circ} \mathrm{C}$. Observations were made with a stereoscopic binocular microscope.Ten replicates were maintainedalongwith a control culture. Experiment was repeated at least once.

\section{Result and Discussion}

The Effect of cadmium salts ( cadmium acetate, cadmium nitrate \& cadmiumsulphate) was studied individually in the concentration range $10^{-8}$ to $10^{-4} \mathrm{M}$.

Cadmium acetate- It had adverse effect on protonemalgrowth. At all the conc. of cadmium acetate tried, inoculums took more time to regenerate and protonemal growth 
Voyager: Vol. IX, No. 1, April 2018, ISSN:(p) 0976-7436 (e) 2455-054x Impact Factor 4.989 (SJIF)

UGC Approved Journal No. 63640

was inhibited (Fig.1). Degree of inhibition increased with increase in concentration. Growth of prostrate system and branching were considerably reduced especially at higher concentrations. Protonema exhibited many abnormalities.

Many filaments showed enlarged terminal and intercalarycells. Gemmae -like structures were produced at all levels(Plate $1-\mathrm{A})$.

Like protonemal growth cadmium acetate also affect bud formation adversely (Fig.1). Their initiation was delayed considerably. Buds appeared after 35, 40, 46, 52 and 55 days at $10^{-8}, 10^{-7}, 10^{-6}, 10^{-5}$ and $10^{-}$ ${ }^{4} \mathrm{M}$, respectively.Buds were highly stunted and possessed highly reduced leaf primordia. Cadmium sulphate- Protonemal growth was adversely affected by cadmium sulphate(Fig.2). At all the levels, regeneration of inoculum was delayed considerably. Branching of protonema was reduced and protonema was pale-green on cadmium sulphate-supplemented media. Athigher concentrations, protonema developed some morphological abnormalities like swelling of terminal and intercalary cells. Gemmae were formed at all levels (Plate 1-B).

Bud formation was also inhibited and it decreased with increase in concentration of cadmium sulphate (Fig.2).Buds were initiated after 38, 42, 50, 52 and 49 days at $10^{-8}, 10^{-7}, 10^{-6}, 10^{-5}$ and $10^{-}$ ${ }^{4} \mathrm{M}$, respectively. Buds failed to develop into normal shoots and formed stunted gametophores with reduced leaf primordia.

Cadmium nitrate- Cadmium nitrate had inhibitory effect on protonemal growth. The degree of inhibition increased with increase in concentration of cadmium nitrate (Fig.3). Protonema was brownish-green on cadmium nitrate- supplemented media. Prostrate system and branching were considerably reduced at higher levels. It also induced many morphological aberrations in the protonema. Many terminaland intercalary cells assumed spherical shape and developed thick walls. Buds appeared after 38, 42, 50 days at 10${ }^{8}, 10^{-7}$ and $10^{-6} \mathrm{M}$ cadmium nitrate. Buds did not develop into normal leafy gametophores but remained stunted with highly reduced leaf primordia. At $10^{-5}$ and $10^{-4} \mathrm{M}$ bud formation was completely inhibited and only gemmae appeared on theprotonema (Plate 1-C)

Bioremediation using mosses is effective method of control of soil pollution created by heavy meatals. Toxicsymptoms on plants were proved to be helpful in identifying the dominant metal of the area and eradicating it using suitable remedial method Various studies indicate that the presence of $\mathrm{Cu}, \mathrm{Zn}, \mathrm{Pb}, \mathrm{Ni}, \mathrm{Cd}$ and $\mathrm{Cr}$ elements may be seriously retard the potential colonization of bryophytes at polluted sites. Cadmium, Copper,Lead and Uranium are heavy metals acting as major atmospheric pollutants.

\section{Conclusion}

Many bryophytes are known to accumulate cadmium in large quantities viz. Sphagnum sp. (Pakarinen\&Tolonen 1976), Rhytidiadelphussquarrosus (Brown 
Effects of Cadmium heavy metal on protonemal growth and bud formation in The Moss Hydrogonoumarcuatum (Griff.) Wijk. \& Marg

Preet Rachna and B.D. Vashistha

and Beckett 1985).On the other hand, some species are sensitive to Cadmium andthese species at various stages of growth and development are inhibited to various degrees. In Funariahygrometrica Cadmium at higher conc. inhibited spore germination (Lepp and Roberts 1977) . Inhibitory effects of protonema and bud formation has been observed in Timmiellaanomala( Kapur\& Chopra 1989). Cadmium higher conc. plays inhibitory role in Pohliaelongata, Atrichumpallidum, Funariahygrometrica, Fissidenstaxifolium (Kaur et al., 2010) and in present study on Hydrogonium.

\section{References}

Borut, S. and Andreas, B.(2002)- International harmonized approach to biomonitoring trace element atmospheric deposition. EnvironPollut. 120: 3-10.

Brown, D.H. and Beckett, R.P. (1985)- Intracellular and extracellular uptake of cadmium by the moss Rhytidiadelphussquarrosus.Ann. Bot. 55:179-188.

Ghate, S. and Chaphekar, S.B. (2000)-Plagiochasmaappendiculatumas a biotest for water quality assessment.Environ. Pollut. 108:173- 181.

Giordano, S; Admo, P.; Sorbo, S. and Vingiani, S. (2005)-Atmospheric trace metal pollution in the naples urban area based on resultsfrom moss and lichen bags. Environ Pollut. 136: 431-442.

Kapur, A. and Chopra, R.N. (1989)- Effect of some metal ions on protonemal growth and bud formation in the moss Timmiellaanomalagrown in aseptic cultures. J. Hattori. Bot. Lab. 66: 283-298.

Kaur, S. ; Rao, A. and Kumar, S.S. (2010)- Studies on the effect of heavy metals on the growth of some bryophytes-1(mosses). Internationaljournal of pharmaceutical sciences review and research $5: \mathbf{1 0 5 - 1 0 7 .}$

Lepp, N.W. and Roberts, M.J. (1977)- Some effects of cadmium on growth of bryophytes. Bryologist 80: 533-536.

Martin, M.H. and Coughtery, P.J. (1982)- Biological monitoring of heavy metal pollution. London applied science publisher.

Pakarinen, P. and Tolonen, R .(1976)- Regional survey of heavy matals in peat mosses Sphagnum Ambio. 5 : 38-40.

Richardson, D.H.S. (1981)- The biology of mosses. Oxford Blackwell publishers.

Ruhling, A. and Tyler, G. (1984)- Recent changes in the deposition of heavy metals in northern Europe. Water, Air and Soil pollution22: 173-180.

Tripathi, A.k. and Gautam, M. (2007)-Biochemical parameters of plants as indicators of air pollution . J. Environ. Boil. 28 : 127-132. 


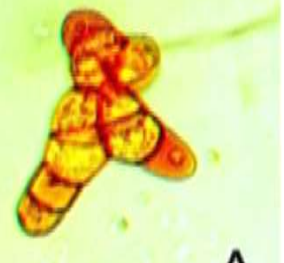

A

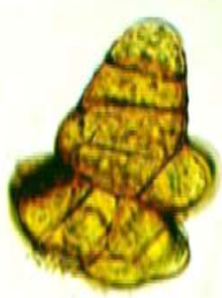

B

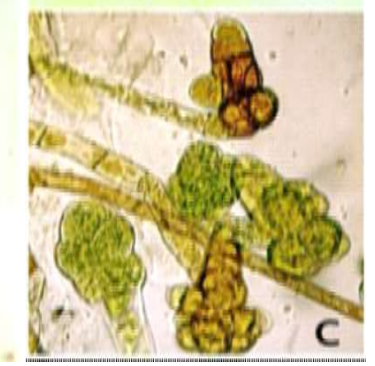

\section{Hydrogoniumarcuatum}

Effect of heavy metals: Production of gemmae like structures:

A.Gemma from cultures supplemented with $10^{-8} \mathrm{M}$ Cadmium acetate;

B.Gemma from cultures supplemented with $10^{-8} \mathrm{M}$ Cadmium sulphate;

C. Gemmae from cultures supplemented with $10^{-5} \mathrm{M}$ Cadmium nitrate

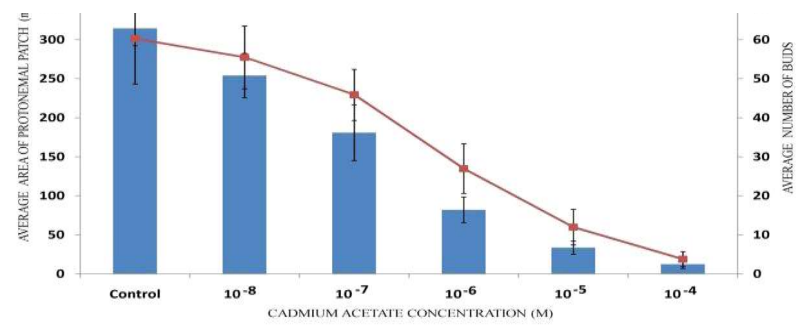

F IG.1 Effect of Cadmium acetate on protonemal grow th and bud form ation in Hydrogoniumarcuatum

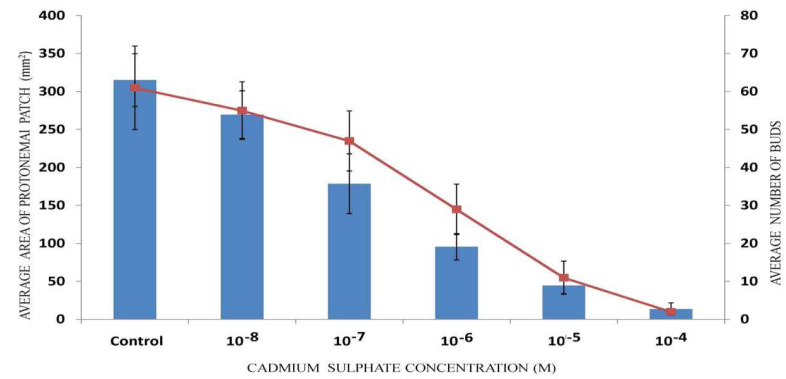

FIG-2. Effect of cadmium sulphate on protonema growth and bud formation in Hydroginiumar cuatum 
Effects of Cadmium heavy metal on protonemal growth and bud formation in The Moss Hydrogonoumarcuatum (Griff.) Wijk. \& Marg

Preet Rachna and B.D. Vashistha

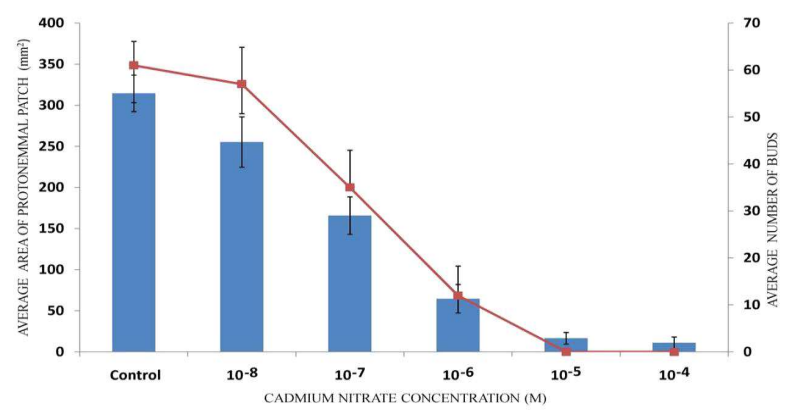

FIG-3. Effect of cadmium nitrate on protonemal growth and bud formation in Hydrogonium arcuatum 